\title{
Effect of Heat Processing and Storage on Characteristic and Stability of Some Edible Oils
}

\author{
Emhemmed A. Alhibshi, Jalal A. Ibraheim and Abdulgader S. Hadad
}

\begin{abstract}
Oils and fats are valuable necessary nutrients that play an important role in human life and health. The purpose of this study is to examine the effect of heat treatment and storage on some food oils, we have selected two of the commonly used in cooking and frying in Libya, namely; two types of olive oil (virgin and olivepomace oil) and two types of corn oil (I and II) for this study. For this purpose we studied the change occurred in some of the physical and chemical properties. These are the refractive index, iodine number, acid value, total acidity, the peroxide value and thiobarbituric acid (TBA) value. The samples were heated at $180{ }^{\circ} \mathrm{C}$ for different periods of time $(5,10,15,20,30$ and 40 hours). Composition of the virgin olive oil sample showed higher value for acid value, total acidity, peroxide number and TBA value and lower value for iodine number than corn oil samples. The highest increase of peroxide number for corn oil (I) was found after 5 hours heating, for corn oil (II) was found after 10 hours heating and for olive oil was found after 30 hours heating. Refractive index increased with increasing heating. Storage of oil samples in colourless glass containers in the dark at room temperature caused increase gradually in the refractive index, acid value and peroxide number in olive oil sample during the six months storage and decrease in iodine number.
\end{abstract}

Keywords-Heat treatment, Storage, Corn oil, Olive oil

\section{INTRODUCTION}

Olive and corn oil are the most commonly used vegetable oils in the household and in Libya for deep frying purposes. The corn oil extracted from corn seed is rich in double unsaturated fatty acid, which is an essential fatty acid. Corn oil is odorless, has very little taste, and has a high smoke point, which makes it suitable for frying [1].

Oils are classified as liquid fats. Seeds are the source of the most of the commercial oils; they are very rich source of energy, enabling the body to absorb certain vitamins (A, D, E, and K). High temperatures affect the omega 3 fatty acids and damaged oils. Hydrogenated fats increase the bad LDL cholesterol and decrease the good HDL cholesterol [2].The elements contained in the fatty acids are: Carbon (C), Hydrogen $(\mathrm{H})$ and Oxygen $(\mathrm{O})$ arranged as a carbon chain skeleton with a carboxyl group (-COOH) at one end [3].

Frying oils have been a hot issue in literature; the topic was approached by many researchers [4 - 6]. Most of the

Emhemmed A. Alhibshi, Faculty of Science, Aljabal Algharbi University.Libya

Jalal A. Ibraheim, Faculty of Science of Engineering and Technology, Sabha University. Libya

Abdulgader S. Hadad, Faculty of Science of Engineering and Technology, Sabha University. Libya common oils are originally extracted from seeds, classified as liquid fats. Oils are very rich source of energy. When oils are exposed to high temperatures the omega 3 fatty acids are affected and therefore damage the oils. [7], [8].

Deep frying is the most common and one of the oldest methods of food preparation worldwide. It involves heat and mass transfer. To reduce the expenses, the oils tend to be used repeatedly for frying. When heated repeatedly, changes in physical appearance of the oil will occur such as increased viscosity and darkening in colour [1], which may alter the fatty acid composition of the oil. Heating causes the oil to undergo a series of chemical reactions like oxidation, hydrolysis and polymerization [9]. During this process, many oxidative products such as hydroperoxide and aldehydes are produced, which can be absorbed into the fried food [9].

Chronic consumption of repeatedly heated vegetable oils could be detrimental to health. It was shown to demonstrate genotoxic and preneoplastic change in the rat liver [10]. It also impaired fluid and glucose intestinal absorption in rats [11]. In rats given alcohol plus heated sunflower, an apparent liver damage as well as increased cholesterol level was observed [12]. Reference [13] found an independent positive association between the risk of hypertension and intake of heated cooking oil. These accumulating data suggest chronic intake of heated cooking oils increases the risk of cancer and cardiovascular diseases [12].

\section{EXPERIMENTAL WORK}

Virgin olive oil samples were obtained from local oil press in Gharian city, Libya. Olive-pomace oil is the oil obtained by treating olive pomace (the product remaining after the mechanical extraction of olive oil) with solvents or other physical treatments, to the exclusion of oils obtained by synthetic processes and mixture with oils of other kinds that is fit for human consumption. The olive-pomace oil samples were obtained from local oil refinery plant, Libya. The corn oil which has been used in the present study were two different samples, one of which was imported from Spain by Nejma company (corn oil I), the other sample was imported,also, from Spain by Alsafawa company (corn oil II). The samples were obtained from the local market in Gharian.

For study the effect of heating, olive-pomace oil, corn oil (I) and corn oil (II) were used, the samples were taken randomly and each one was heated in three aluminum containers, at $180^{\circ} \mathrm{C}$ for 40 hours and the analysis were carried out at different time intervals $(0,5,10,15,20,30$ and 40$)$. 
For study the effect of storage on olive oil, the samples were stored in Colorless glass container of $50 \mathrm{ml}$ and sealed carefully and stored for six months at room temperature $\left(25^{\circ} \mathrm{C}\right)$ and were sampled periodically every one month. Refractive indices of all samples were determined at $20-25^{\circ} \mathrm{C}$ by AbbRefractometer according to AOAC (1984) [14]. Acid value, total acidity (as oleic acid percentage), iodine number and the peroxide number were determined according to AOAC (1984) [14], thiobarbituric acid value was determined according Pearson (1981) [15].

\section{RESULTS AND DISCUSSIONS}

The studied properties of oil sample determine the quality of these samples. Lipid oxidation is one of the major causes of food spoilage. It is of great economic concern to the food industry because it leads to the development, in edible oils and fat-containing foods, of various off-flavors and off-odors generally called rancid, which renders these foods unacceptable or reduces their shelf life [16]. Table 1 shows some physical and chemical properties of all samples, it showed that the properties of all samples were close to international standards [17]. Compared to corn oil (I), lower iodine number for corn oil (II) and higher peroxide number which could be due to different storage conditions. The differences in iodine values between the samples are due to their fatty acid compositions where corn oil (I) contains more unsaturated fatty acids than the other samples while virgin olive oil contains the lowest, these differences play important role in oxidation of these oils [17].

TABLE 1

The Measured Physical And Chemical Properties Of Oil SAMPLes

\begin{tabular}{|c|c|c|c|c|c|}
\hline & $\begin{array}{c}\text { Corn oil } \\
\text { (I) }\end{array}$ & $\begin{array}{c}\text { Corn } \\
\text { oil (II) }\end{array}$ & $\begin{array}{c}\text { olive- } \\
\text { pomace } \\
\text { oil }\end{array}$ & $\begin{array}{c}\text { Virgin } \\
\text { olive } \\
\text { oil }\end{array}$ & L.S.D \\
\hline $\begin{array}{c}\text { Refractive } \\
\text { index }\end{array}$ & 1.4670 & 1.4648 & 1.4658 & 1.4686 & NS \\
\hline $\begin{array}{c}\text { Acid } \\
\text { number }\end{array}$ & 0.21 & 0.31 & 0.44 & 4.37 & 0.09 \\
\hline Total acidity & 0.11 & 0.16 & 0.22 & 2.19 & 0.05 \\
\hline $\begin{array}{c}\text { Iodine } \\
\text { number }\end{array}$ & 110.85 & 103.98 & 91.07 & 81.14 & 3.41 \\
\hline $\begin{array}{c}\text { Peroxide } \\
\text { number }\end{array}$ & 2.02 & 5.86 & 9.84 & 7.81 & 0.74 \\
\hline $\begin{array}{c}\text { Thiobarbituric } \\
\text { acid value }\end{array}$ & 0.36 & 0.44 & 1.30 & 3.02 & 0.05 \\
\hline
\end{tabular}

The refractive indices of all samples is varied between 1.4648 and 1.4686, while the standard values are between 1.4650 and 1.4680 measured at $40^{\circ} \mathrm{C}$. The refractive index of an oil increases (nonlinearly) with chain length and unsaturation of fatty acids. The refractive indices and peroxide values of the oils and fats can significantly increase while exposed to light and heat [17]. Virgin olive oil recorded the highest TBA value while the lowest was with corn oil (I). TBA value usually is more sensitive at the early stages of oxidation and the oxidation products such as unsaturated fatty acids particularly linolenic acid is responsible for developing the colour clearly with TBA and the compound formed as a result of the oxidation of unsaturated fatty acids is malonialdyde [18].

The effect of heating on refractive indices is shown in Fig. 1 , it seems that the refractive index increases with increasing the heating time where it reaches the maximum value with all samples after 40 hours of heating.

Refractive index of oil can be used to detect rancidity in edible oil, it is also provides useful information about the purity of oils. Each oil has certain range for this parameter and deviation of the data from the set specification may indicate adulteration of oil [18], [19].

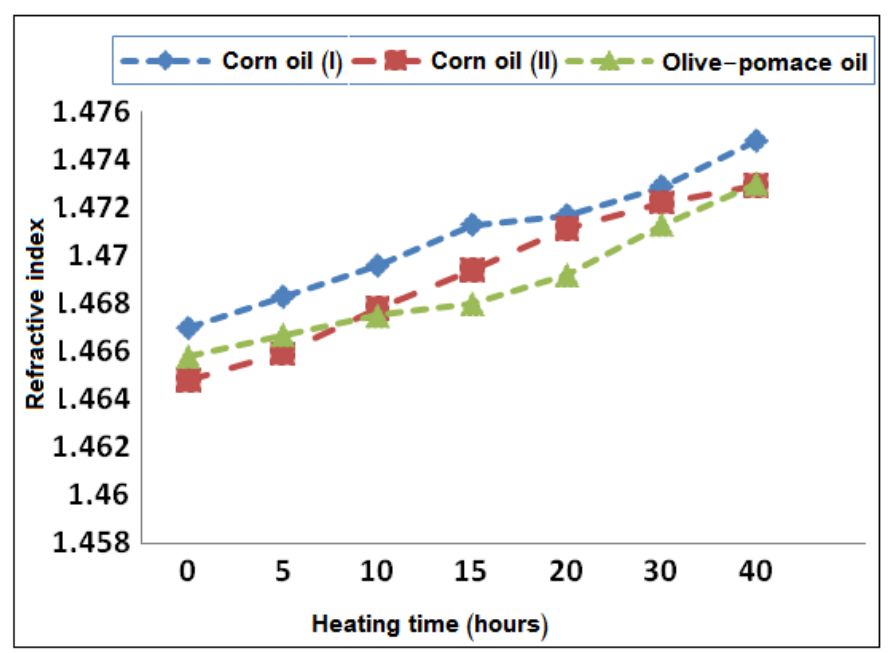

Fig. 1 Effect of heating on refractive indices of oil samples

The effect of heating on acid number is shown in Fig. 2, it seems that the acid number increases with increasing the heating time where it reaches the maximum value with all samples after 40 hours of heating. After 5 hours of heating, corn oil (II) showed less increase than the other samples, acid number of olive-pomace oil was 0.60 which is the maximum allowable limit in International standards [17].

The acid number test is one of the methods available in the oil analysis field used to estimate the oxidation. Acid value does not directly measure the rate of oxidation, it merely measures the by-product of oxidation [20]

In normal circumstances, refined oils should be free from any free fatty acids. Oils, on decomposition-due to chemical or physical factors-yield free fatty acids. Usually, acid number is used to determine the quality of oils, where it shows the amount of free fatty acid present in the oil samples. The results showed that the oil samples shouldn't be used for frying with more than 10 hours [21], [22]. 


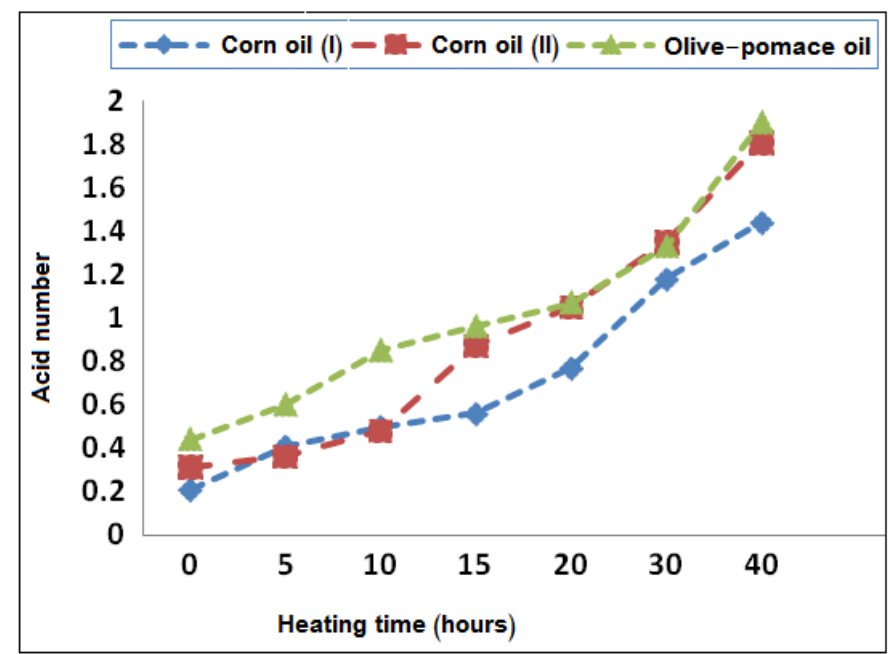

Fig. 2 Effect of heating on acid numbers of oil samples

The effect of heating on total acidity is shown in Fig. 3. The results showed that the total acidity of corn oil (I) sample increased by almost $100 \%$ after 5 hours of heating which was similar to the increase in acid number (Fig. 2). After 5 hours of heating, total acidity of olive-pomace oil was increased to $0.30 \%$ and after 10 hours of heating, total acidity of corn oils (I and II) was increased to 0.25 and $0.24 \%$ respectively, which were close to the maximum allowable limit in International standards [17].

In general, the total acidity of all samples increases with increasing the heating time where it reaches the maximum value with all samples after 40 hour of heating which agreed with older studies [22 ], [23]. Increasing of total acidity may due to decomposition of some phospholipids and triacylglycerols to glycerol and free fatty acids.

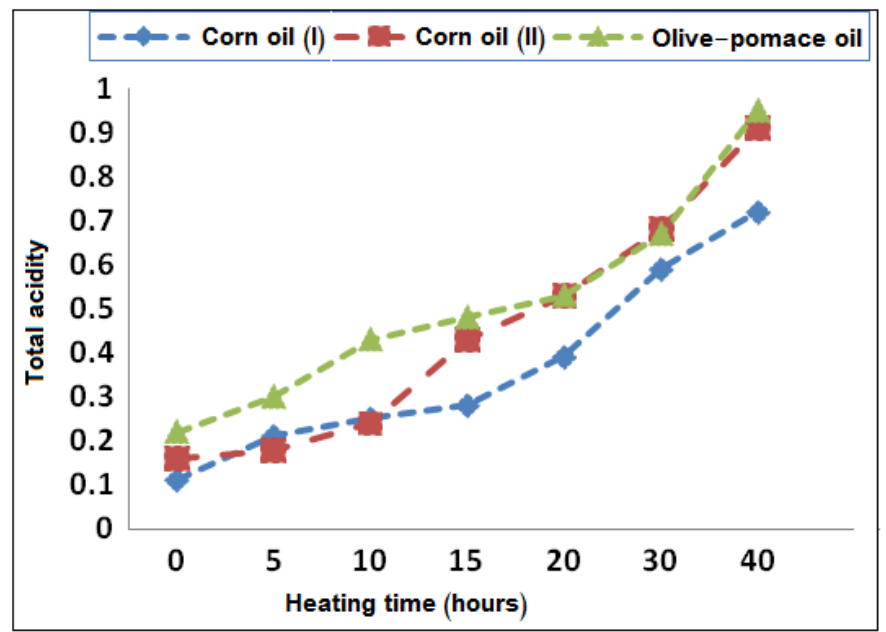

Fig. 3 Effect of heating on total acidity of oil samples

The molecular structure of fats and oils play a role in autoxidation. Oils with a high degree of unsaturation are most susceptible to autoxidation.. Iodine number is useful to know the relative unsaturation of fats, and is directly proportional to the content of unsaturated fatty acids [24]. Thus lower is the iodine number, less is the degree of unsaturation. The effect of heating on iodine values is shown in Fig. 4, it seems that the iodine value decreases with increasing the heating time where it reaches the minimum value with all samples after 40 hours of heating. It seems that olive-pomace oil was less affected by heating among the samples, the iodine number after 40 hours was 73.9 which was less than the minimum limit in International standards [17] which is 75.0. Reference [23] showed that iodine value of soy, sunflower and palm oils were less affected by frying and storage time.

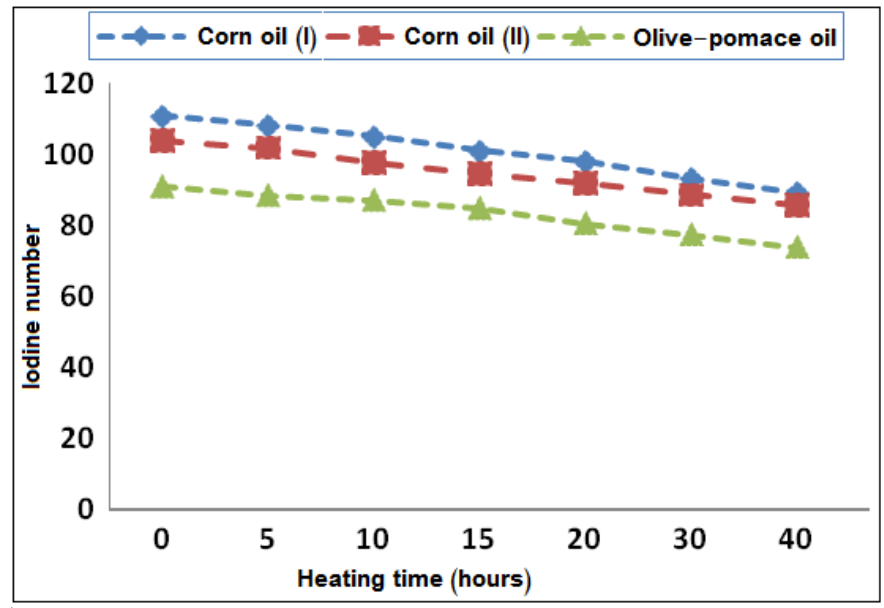

Fig. 4 Effect of heating on iodine numbers of oil samples

It shows that high increase of peroxide value was after 5 hours heating. Generally, increasing of the peroxide value is proportional to the heating time, the results showed that the maximum peroxide value for corn (I) after 5 hours heating, for corn oil (II) after 10 hours and for olive-pomace oil after 30 hours. It is difficult to provide a specific guideline relating peroxide value to rancidity. The effect of heating on peroxide values is shown in Fig. 5.

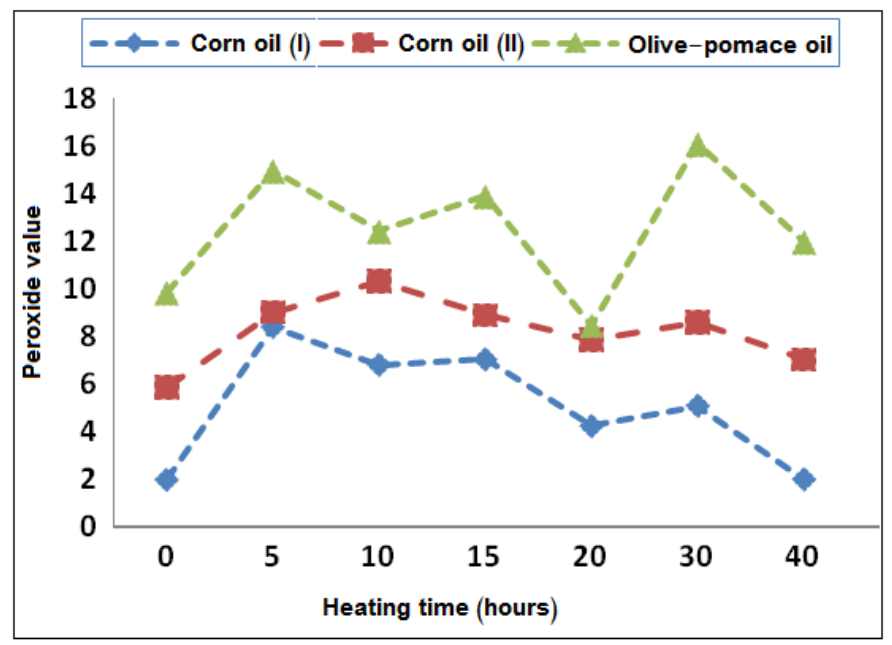

Fig. 5 Effect of heating on peroxide values of oil samples

The Peroxide value of an oil or fat is used as a measurement of the extent to which oxidation reactions have occurred during processing and storage. Other methods are available but 
peroxide value is the most widely used. The best test for autoxidation (oxidative rancidity) is determination of the peroxide value, as peroxides are intermediates in the autoxidation reaction. Autoxidation is a reaction involving oxygen that leads to deterioration of fats and oils which form off-flavours and off-odours. Peroxide value, which is the concentration of peroxide in an oil or fat, is useful for assessing the extent to which spoilage has occurred [25].

Peroxide values of fresh oils are less than 10 milliequivalents $/ \mathrm{kg}$, when the peroxide value is between 30 and 40 milliequivalents $/ \mathrm{kg}$, a rancid taste is noticeable. High peroxide values are a definite indication of a rancid fat, but moderate values may be the result of depletion of peroxides after reaching high concentrations [26], [27].

Fig. 6 represent the effect of heating time on thiobarbituric acid (TBA) value, it shows higher increase with olive-pomace oil after 15 hours heating than other oils while corn (I) oil showed high increase after 10 hours and then decreased after 20 hours of heating, also, corn oil (II) showed increase after 20 hours and decrease after 30 hours of heating. It seems that the increase and decrease of TBA value as a function of time of heating depend on the amount of malondialdehyde produced.

The most prominent and currently used assay as an index for lipid peroxidation products is the thiobarbituric acid assay. It is based on the reactivity of an end product of lipid peroxidation, malondialdehyde with TBA to produce a red adduct [28].

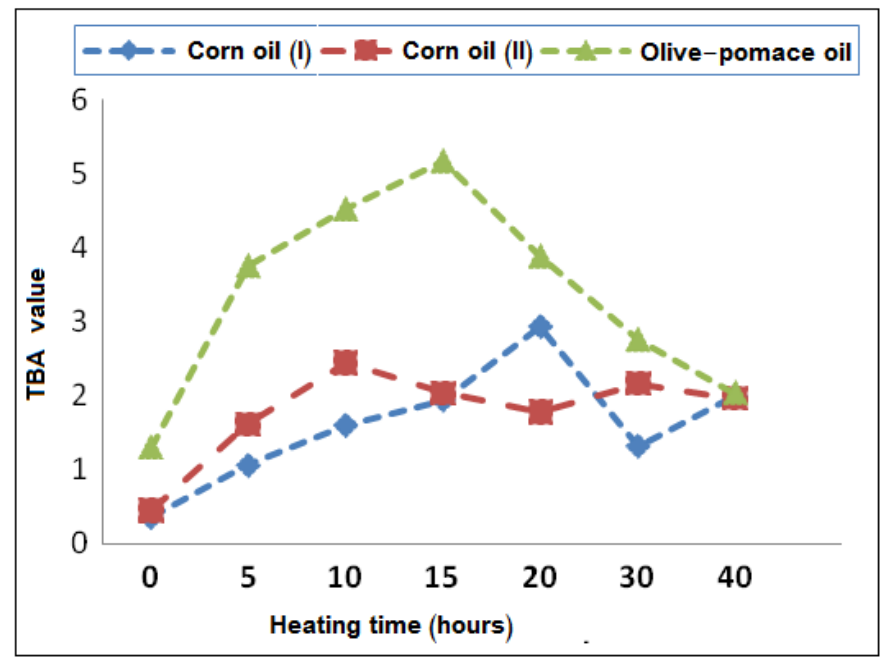

Table 2 shows the effect of storage time on some properties of virgin olive oil samples. As a result of oxidation of the oil sample during storage, the index of refraction, acid number, total acidity and the peroxide values were increased with storage period, it was at the maximum after 6 months of storage while the iodine value decreased during the storage time which could be due to the decreasing the number of unsaturated fatty acids during the oxidation of the oil sample. Similar results were obtained [29] when different types of oils were stored under different conditions such as temperature and light. Presence or addition of antioxidants such as tocopherols could protect oils or reduce the oil oxidation [30]-[34].
TABLE II

The EFFect Of Storage ON SOME Properties Of VIRGIN Olive OIL SAMPLES

\begin{tabular}{|c|c|c|c|c|c|}
\hline $\begin{array}{c}\text { Storage } \\
\text { time } \\
\text { (months) }\end{array}$ & $\begin{array}{c}\text { Refractive } \\
\text { index }\end{array}$ & $\begin{array}{c}\text { Acid } \\
\text { number }\end{array}$ & $\begin{array}{c}\text { Total } \\
\text { acidity }\end{array}$ & $\begin{array}{c}\text { Iodine } \\
\text { number }\end{array}$ & $\begin{array}{c}\text { Peroxide } \\
\text { number }\end{array}$ \\
\hline 0.0 & 1.4686 & 4.37 & 2.19 & 81.14 & 7.81 \\
\hline 1.0 & 1.4688 & 4.70 & 2.37 & 80.70 & 9.28 \\
\hline 2.0 & 1.4690 & 5.06 & 2.55 & 79.93 & 11.61 \\
\hline 3.0 & 1.4694 & 5.37 & 2.70 & 79.52 & 13.06 \\
\hline 4.0 & 1.4699 & 5.52 & 2.78 & 79.16 & 14.93 \\
\hline 5.0 & 1.4702 & 5.79 & 2.91 & 78.35 & 17.06 \\
\hline 6.0 & 1.4708 & 5.97 & 3.00 & 77.90 & 19.19 \\
\hline L.S.D & NS & 011 & 0.18 & 0.51 & 0.23 \\
\hline
\end{tabular}

\section{CONCLUSION}

In this research work we examined the effect of heating and storage on different oil samples that commonly used in cooking and frying. The results deduced from this research confirmed that cooking at high temperatures and six months storage will alter the properties of the oils, if not damaged them. This reflects a change in the chemical structures of the oils. Also one concluded that the concentration of some of the basic elements that constitute the oil such as oxygen and carbon has been noticeably changed. The recommendation drawn from this study is that; frying oils must not be used more than one time, since their properties will be changed. Repetition of re-heating oils to their boiling temperatures will damage them. The chemical structures will be distorted implying a possibility of changing the oils into harmful substances.

\section{REFERENCES}

[1] Tamador S. Saeeda and Omer I. Eid (2014): Thermal and Optical investigation of Corn and Cottonseed as Frying Oils, Sudan Journal of Science (SJS)| http://sciencejournal.uofk.edu.

[2] Iris Erlund, Raika Koli, Georg Alfthan, Jukka Marniemi, Pauli Puukka, Pirjo Mustonen1(2008), Pirjo Mattila, and Antti Jula, Am J Clin Nutr, $87,2,323-331$.

[3] Smith, J. G. (2006): "Organic Chemistry", McGraw Hill.

[4] Melton, S. L. Sajida Jafar, Danielle Sykes, M. K. Trigiano (1994): Journal of the American Oil Chemists' Society, 71, 1301-1308. https://doi.org/10.1007/BF02541345

[5] Huseyin Sanlia, c, Mustafa Canakcib, c, Ertan Alptekinb, c, Fuel (2014), 115, 850-854.

[6] Hong-Sik Hwang, Kenneth M. Doll, Jill K. Winkler-Moser, Karl Vermillion, Sean X. Liu (2013), Journal of the American Oil Chemists' Society, 2013, 90, 825-834. https://doi.org/10.1007/s11746-013-2229-9

[7] http:// gooskalic.columbia.edu/0768.html.

[8] www.unu.edu/unupress/food/8F083F03.htm

[9] Santos, J.C.O. , Santos, I.M.G., Souza, A.G. (2005). Effect of heating and cooling on rheological parameters of edible vegetable oils. Journal of Food Engineering, 67, 401-405. https://doi.org/10.1016/j.jfoodeng.2004.05.007

[10] Srivastava, S., M. Singh, J. George, K. Bhui, Saxena. A. Murari, Y. Shukla (2010): Genotoxic and carcinogenic risks associated with the dietary consumption of repeatedly heated oconut oil. Br. J. Nutr. 104913431352.

[11] Obembe AO, Owu DU, Okwari OO, Antai AB, Osim EE2011Intestinal Fluid and Glucose Transport in Wistar Rats following Chronic Consumption of Fresh or Oxidised Palm Oil Diet. ISRN Gastroenterol (2011): 972838. 
[12] P. Latha, D. Chaitanya, R. Rukkumani (2010): Protective effect of Phyllanthus niruri on alcohol and heated sunflower oil induced hyperlipidemia in Wistar rats. Toxicol Mech. Methods. 208498503

[13] F. Soriguer, G. Rojo-Martínez, M. C. Dobarganes, Almeida. J. M. García, I. Esteva, M. Beltrán, Adana. Ruiz De, F. Tinahones, J. M. Gómez-Zumaquero, E. García-Fuentes, S. González-Romero (2003): Hypertension is related to the degradation of dietary frying oils. Am. J. Clin. Nutr. 78610921097

[14] A.O.A.C. (1984): Official methods of analysis of association of official analytical chemists $14^{\text {th }}$ ed. Washington D.C. USA.

[15] Pearson,D. (1981): The chemical analysis of food, National College of Food technol. Univ. of Reading. Weydridge. Surry, J. and Chirehill, A.

[16] Edem DO (2002): Palm oil: biochemical, physiological, nutritional, hematological, and toxicological aspects: a review. Plant Foods Hum. Nutr. 57(3-4): 319-341. https://doi.org/10.1023/A:1021828132707

[17] FAO/WHO (1983): Coden standard for edible fats and oils, Vol. XI, firest edition food and agriculture organization.

[18] Valde's, F. Adolfo, B. Garcia, Ana (2005). A study of the evolution of the physicochemical and structural characteristics of olive and sunflower oils after heating at frying temperatures.

[19] Kim, Juyoung, Kim, Deok Nyun, Lee, Sung Ho,Yoo, Sang-Ho, Lee , Suyong (2006). Correlation of fatty acid composition of vegetable oils with rheological behaviour and oil uptake. Food Chemistry, 118, 398-40. https://doi.org/10.1016/j.foodchem.2009.05.011

[20] Kardash, E. and Tur'yan, Y. I. (2005): Acid Value Determination in Vegetable Oils by Indirect Titration in Aqueous-alcohol Media. Croat. Chem. Acta 78:1:99-103.

[21] Bocca, A., Fabietti, F. and Pagano, M.A. (1990). Analytical characteristics of extra virgin olive oil in canned vegetables. Revista della Societa Italiana di Scienza dell'Alimentazione, 19(1-2), 39-43.

[22] Abdul-Elmalek, G. S., El-gaimy, M. A. and El-sayed, M. E. (1989): Analytical studies on some olive oil varieties. Second conference of food science and technology for Mediterranean countries. Cairo, 371378.

[23] Abd-elal, M. H. and Karara, H. A. (1986): Changes in corn oil during deep frying of foods, J. Lebens mittel-wiss-u-technol. 17 (4): 232-235.

[24] Satyanarayana, U. and Chakrapani, U. (20110: Biochemistry, Books and Allied (P) LTD, Beliaghata main road, Kolkata 700010 India.

[25] Bradley, D. G. and Min, D. B. (1992): Singlet oxygen oxidation of foods, Crit. Rev. Food Sci. Nutr., 31, 211. https://doi.org/10.1080/10408399209527570

[26] Choe, E., D. B. Min, 2006Chemistry and reactions of reactive oxygen species in foods. Crit. Rev. Food Sci. Nutr. 461122 https://doi.org/10.1080/10408390500455474

[27] Kamsiah J. and Yusof K. (2012): Repeatedly Heated Vegetable Oils and Lipid Peroxidation, "Lipid Peroxidation", book edited by Angel Catala, ISBN 978-953-51-0716-3.

[28] Garcia $\mathrm{YJ}^{1}$, Rodríguez-Malaver AJ, Peñaloza N. (2005): Lipid peroxidation measurement by thiobarbituric acid assay in rat celebellar slices, J Neurosci Methods. 15;144(1):127-35.

[29] Christine Stark, D.L. McNeil and G.P. Savage (2000): The effect of storage conditions on the stability of peroxide values of New Zealand grown walnuts. Proceedings of the Nutrition Society of New Zealand, 2000, Vol. 25.

[30] Bardhan, J., R. Chakraborty, U. Raychaudhuri, 2011The 21st century form of vitamin E- Tocotrienol. Curr. Pharm. Des. 172121962205. https://doi.org/10.2174/138161211796957472

[31] Abbas AM, Elsamanoudy AZ2011Effects of 17ß-estradiol and antioxidant administration on oxidative stress and insulin resistance in ovariectomized rats. Can. J. Physiol. Pharmacol. 897497504 https://doi.org/10.1139/y11-053

[32] Quiles, M. C. Ramírez-Tortosa, S. Ibáñez, González. J. Alfonso, G. G. Duthie, J. R. Huertas, J. Mataix, 1999Vitamin E supplementation increases the stability and the in vivo antioxidant capacity of refined olive oil. Free Radic. Res. 31 Suppl: S129S135.

[33] Bardhan, R. Chakraborty, U. Raychaudhuri, 2011The 21st century form of vitamin E- Tocotrienol. Curr. Pharm. Des. 172121962205. https://doi.org/10.2174/138161211796957472
[34] Narang, D., S. Sood, M. Thomas, A. K. Dinda, S. K. Maulik, 2005Dietary palm olein oil augments cardiac antioxidant enzymes and protects against isoproterenol-induced myocardial necrosis in rats. J. Pharm. Pharmacol. 571114451451. https://doi.org/10.1211/jpp.57.11.0010 